\title{
AÇÕES EXTENSIONISTAS DO IFSP SÃO ROQUE NO ENFRENTAMENTO AOS EFEITOS DA COVID-19
}

\section{IFSP SÃO ROQUE EXTENSIONIST ACTIONS ADDRESSING THE COVID-19 \\ EFFECTS}

\author{
Gabriela Garcia Medeiros ${ }^{1}$ \\ Luiz Felipe Borges Martins ${ }^{2}$ \\ Mariana Neves Vieira ${ }^{3}$ \\ José Lucio da Silva Santos ${ }^{4}$ \\ João Daniel Matos ${ }^{5}$ \\ Christine Hauer Piekarz ${ }^{6}$
}

\begin{abstract}
Resumo: O ano de 2020 está sendo marcado por uma transformação nos hábitos de convívio social devido à COVID-19. Por causa da sua alta transmissibilidade, em pouco tempo, essa enfermidade recebeu o status de pandemia, trazendo preocupação e mudanças de hábitos no mundo todo. Por se tratar de uma doença ainda sem tratamento e vacina eficazes - que pode evoluir para casos graves e levar ao óbito - medidas de emergência, como o distanciamento social, foram tomadas com o objetivo de controlar a propagação do vírus, o que fez com que instituições de ensino e serviços presenciais não essenciais fossem interrompidos e, assim, a população ficasse sem contato pessoal direto, como era de costume. Essas mudanças vieram de forma abrupta, trazendo as mais diversas consequências e uma nova rotina que pode provocar medos, angústias, ansiedade, entre outros. Partindo dessa nova realidade, o presente trabalho, de ação extensionista, teve como objetivo auxiliar a comunidade externa e interna do Instituto

\footnotetext{
${ }^{1}$ Bióloga; Mestre em Ciências/Ecologia Aplicada. Professora de Ensino Básico, Técnico e Tecnológico no Instituto Federal de Educação, Ciência e Tecnologia de São Paulo - Campus São Roque, São Roque, São Paulo, Brasil. E-mail:gabigarcia.medeiros@hotmail.com

${ }^{2}$ Gestor Ambiental; Mestre em Ciências/Ecologia Aplicada. Professor de Ensino Básico, Técnico e Tecnológico no Instituto Federal de Educação, Ciência e Tecnologia de São Paulo - Campus São Roque, São Roque, São Paulo, Brasil.

${ }^{3}$ Discente do Ensino Médio Integrado ao Técnico em Alimentos; Instituto Federal de São Paulo - Campus São Roque, São Roque, São Paulo, Brasil. E-mail: marineves2003@gmail.com.

${ }^{4}$ Graduando em Administração; Instituto Federal de São Paulo - Campus São Roque, São Paulo, Brasil. E-mail: luciosantos95@gmail.com

${ }^{5}$ Discente do Ensinou Médio Técnico em Meio Ambiente, Instituto Federal de São Paulo - Campus São Roque, São Roque, São Paulo, Brasil. E-mail: juoodaniel@gmail.com

${ }^{6}$ Médica Veterinária; Mestre em Ciências Veterinárias. Técnica Administrativa em Educação, Instituto Federal de São Paulo - Campus São Roque, São Roque, São Paulo, Brasil. E-mail: christine.piekarz@ifsp.edu.br.
} 
Federal de São Paulo, campus São Roque, levando informações de forma segura à população sobre o vírus e buscando minimizar algumas consequências que vieram com a pandemia, através de lives, publicações em redes sociais e outras ações, abordando temas recorrentes, como: controle da ansiedade, prevenção ao suicídio, necessidade da manutenção das medidas preventivas da Covid-19 e importância da prática de esportes durante o isolamento. As ações tiveram as redes sociais como base de realização e divulgação, obtendo, assim, um alcance significativo já que possibilitou o acesso irrestrito às informações e favoreceu sua propagação. Palavras-chave: Coronavírus. Extensão. Isolamento social. Pandemia. Sars-Cov-2.

Abstract: Covid-19 has transformed the social habits and interactions, marking the year of 2020. Because of its high transmissibility, in a short period, this disease has been classified as a pandemic, causing concern and habit changes worldwide. As it still without an effective treatment or vaccine and the disease can also progress to severe cases and lead to death, emergency measures, such as social distance, were taken aiming to control the spread of the virus. It caused the interruption of educational institutions and non-essential services, making the population out of personal contact with each other. These changes came unexpected, bringing the most diverse consequences and a new routine that can cause fear, anxiety, stress, and others. Considering this a new reality, the present extension study aimed to help the external and internal community of the Federal Institute of São Paulo, São Roque campus, bringing reliable information to the population about the virus and seeking to minimize some consequences that came with the pandemic, through internet videos, posts on social media and other actions, addressing themes, such as: anxiety control, suicide prevention, the need to maintain preventive measures at Covid-19 and also showing the importance of keep doing physical activities during social isolation. The actions had social media as means of communication, reaching a significant visibility and dissemination, since it allowed unrestricted access and the spread of information.

Keywords: Coronavirus. Extension. Social Isolation. Pandemic. Sars-Cov-2.

\section{Introdução}

Em dezembro de 2019, um surto de pneumonia foi reportado na cidade de Wuhan, na China, (ZHU et al., 2020). Aproximadamente um mês após esses primeiros relatos, a Organização Mundial de Saúde (OMS, 2020) declarou o surto como uma preocupação internacional de emergência da saúde pública e, no dia 11 de março de 2020, reconheceu-se então a doença, Covid-19, como uma pandemia (OMS, 2020). A pandemia trouxe, como uma 
de suas consequências, a necessidade do mundo se adaptar em pouco tempo a uma nova rotina.

A Covid-19 é causada pelo vírus Sars-Cov-2, um organismo que possui ácido ribonucleico (RNA) como material genético e é envelopado por uma cápsula de lipídios e proteínas. As glicoproteínas spike (S) do Sars-Cov-2 são o que caracteriza esse vírus como corona, pois são proeminentes e fazem o vírus parecer estar usando uma coroa de espinhos (WANG et al., 2020). A spike S liga-se às células do hospedeiro através do receptor Angiotensin Converting Enzyme (ACE2) e as invade, controlando as funções celulares (KIRCHDOERFER et al., 2020; ZHENG et al., 2020). Os principais sintomas apresentam-se como: diarreia, náusea, febre, dores no corpo e dores de cabeça, porém, muitas pessoas podem ser assintomáticas (CHAN et al., 2020), ou seja, não apresentam sintomas. As medidas preventivas e de controle da propagação da Covid-19 incluíram, nos últimos meses, a detecção e diagnóstico precoce dos doentes, o tratamento dos doentes, medidas de distanciamento social e, até mesmo, períodos de quarentena para diminuir a rápida transmissão entre os humanos (WHO, 2019).

A pandemia causada pela Covid-19 é considerada um dos maiores desafios mundiais do século 21 (BARRETO et al., 2020). No mundo, até o dia 30 de setembro de 2020, havia mais de 1 milhão de mortes registradas (JOHNS HOPKINS UNIVERSITY, 2020), entre essas, aproximadamente 144 mil ocorreram no Brasil (BRASIL, 2020a). Desta forma, é evidente a necessidade da manutenção de ações que incentivem a vivência e as trocas de experiências e saberes entre as instituições de ensino e a comunidade.

A extensão é uma dimensão educativo-dialógica que proporciona a formação dos estudantes e o desenvolvimento local, por meio da realização de ações articuladas entre a comunidade acadêmica e as demandas sociais. Não se trata, portanto, de uma invasão ou uma comunicação, mas de uma relação com base no diálogo. De acordo com a Lei nº 11.892 , de 29 de dezembro de 2008 (BRASIL, 2008), os Institutos Federais de Educação, Ciência e Tecnologia devem desenvolver atividades de extensão, respeitando os princípios e finalidades da educação profissional e tecnológica, em articulação com o mundo do trabalho e os segmentos sociais, e com ênfase na produção, desenvolvimento e difusão de conhecimentos científicos e tecnológicos. 
O documento norteador do Instituto Federal de São Paulo (IFSP) defende que as áreas temáticas da Extensão reflitam seu caráter interdisciplinar, contemplando: Comunicação; Cultura; Direitos Humanos e Justiça; Educação; Meio Ambiente; Saúde; Tecnologia e Produção e Trabalho. Portanto, perpassam por diversas discussões que emergem na contemporaneidade como, por exemplo, a diversidade cultural, contribuindo para a democratização de debates e da produção de conhecimentos amplos e plurais no âmbito da educação profissional, pública e estatal (PDI, 2019). Por fim, a relação instituição/comunidade não se pode resumir a simples trocas de serviços ou equipamentos, por isso, o seu real objetivo deve ser o aumento da base de conhecimento das duas instituições. Tais relações podem assumir várias formas, desde uma simples consultoria até a construção de estruturas especiais e complexas (VASCONCELOS; FERREIRA, 2000).

Dessa forma, apoiada pelo princípio da indissociabilidade entre Ensino, Extensão e Pesquisa, conforme preconizado no artigo 207, da Constituição Federal de 1988 (BRASIL, 1988), a extensão propicia um espaço privilegiado de vivências e de trocas de experiências e saberes, promovendo a reflexão crítica dos envolvidos e impulsionando o desenvolvimento socioeconômico, equitativo e sustentável (BRASIL, 2019). Desta forma, e também fundamentado nos estudos do educador brasileiro Paulo Freire (1992), que sustenta os princípios de uma educação emancipadora, este projeto busca contextualizar a vida real e cotidiana dos indivíduos das comunidades interna (alunos, servidores e terceirizados) e externa com os processos de ensino e aprendizagem nos quais se pretende envolver estes sujeitos. Além disso, o presente projeto não se fecha em apenas uma área de atuação, tendo abertura para atender às diferentes demandas que surgem e que estão ao alcance da instituição.

\section{Objetivo}

O objetivo das ações desenvolvidas no projeto de extensão intitulado "Ações Extensionistas do IFSP São Roque no enfrentamento dos efeitos da Covid-19” envolveu o atendimento de demandas identificadas em ação conjunta com a comunidade externa e também

$$
\begin{array}{l|l}
\multirow{2}{*}{\text { REVISTA }} & \text { EXTENSÃO \& CIDADANIA } \\
\cline { 2 - 3 } & \text { v. 8, n. 14, p. 248-265, jul./dez. 2020. ISSN 2319-0566 }
\end{array}
$$


interna do campus São Roque, do Instituto Federal de São Paulo (IFSP/SRQ) em relação às consequências observadas decorrentes da nova realidade imposta pelo novo coronavírus. Buscou-se o atendimento, em consonância com os arranjos coletivos locais, apresentar oportunidades e informações para o público atendido, que envolveram crianças, jovens, adultos e idosos.

\section{Metodologia}

O projeto intitulado “Ações Extensionistas do IFSP São Roque no Enfrentamento dos efeitos da Covid-19" teve início efetivo em 1 de agosto de 2020 e, durante dois meses de atuação, realizou lives, postagens em redes sociais e ações que tiveram como objetivo informar e aproximar a Instituição da comunidade interna e externa ao campus.

O projeto utilizou contas nas redes sociais Instagram e Facebook - @ifsp.saoroque.cex e Projeto-Covid SRQ - e foram feitas 21 postagens no Instagram e no Facebook no total. Essas postagens apresentaram informações relevantes, retiradas de fontes de confiança e explicadas de uma forma simples, facilitando a compreensão dos seguidores das redes sociais. As imagens publicadas foram feitas utilizando programas de edição gráfica com o intuito de apresentar maior atratividade visual.

Além das publicações efetuadas nas redes sociais, foram realizadas duas lives, ou seja, encontros síncronos com a interação dos participantes no Youtube, através do canal IFSP-SRQ no Enfrentamento aos Efeitos da COVID, criado pelo projeto. No dia 25 de agosto de 2020, foi realizada a live "Pandemia e seus efeitos psicológicos" e, no dia 26 de setembro de 2020, ocorreu a segunda live com o título "Prevenção do suicídio". As duas lives foram desenvolvidas em parceria com profissionais de Psicologia, com capacitação para expor sobre temas complexos da saúde mental. Para a realização da live utilizou-se a plataforma StreamYard. Ambas palestras são mantidas disponíveis no Youtube para a visualização por quem se interessar pelo tema.

Além de lives e postagens, o projeto realizou ações como o incentivo à prática de

$$
\begin{array}{l|l}
\multirow{2}{*}{\text { REVISTA }} & \text { EXTENSÃO \& CIDADANIA } \\
\cline { 2 - 3 } & \text { v. 8, n. 14, p. 248-265, jul./dez. 2020. ISSN 2319-0566 }
\end{array}
$$


atividades físicas em casa durante o período da pandemia, doação de cestas básicas e outra em comemoração ao Dia das Crianças. A primeira efetivou-se com a realização de um minicurso, online e gratuito de prática de yoga ministrado por uma professora convidada. Após inscrições prévias pela plataforma online de eventos Sympla, três aulas ocorreram, através do aplicativo Zoom, nos dias 26 de setembro, 3 e 10 de outubro de 2020.

A ação de doação de cestas básicas foi uma colaboração a um projeto iniciado em abril de 2020 pelo Grêmio Estudantil Mário de Andrade do IFSP/SRQ, com o intuito de ajudar famílias de alunos e a comunidade de São Roque. O projeto contou também com a ajuda de pessoas da comunidade e do apoio do Comitê de Mobilização Estadual, formado por estudantes de diversos campi do Instituto Federal de São Paulo, que já realizavam a campanha em outras cidades do estado. Iniciou-se com a divulgação da ideia, solicitando local para armazenar e preparar os kits a serem doados, aceitando doações de alimentos e produtos de higiene. Ao total, foram cerca de 60 cestas básicas doadas às famílias de São Roque e região.

A ação voltada para o Dia das Crianças ocorreu com a elaboração e entrega de um caderno de atividades e giz de cera ou lápis de cor às crianças carentes do bairro em que o campus São Roque se localiza. Esse livreto foi inteiramente idealizado e produzido pela equipe do projeto. Composto por história em quadrinhos (HQ), desenhos para colorir, caça palavras e labirinto, a arte foi desenhada e escrita levando por base informações relevantes e obtidas de fontes confiáveis sobre a Covid-19, com a preocupação de serem compreendidas por crianças de diferentes idades. Os desenhos foram feitos inicialmente à mão e utilizou-se os programas de edição gráfica para aprimoramento e finalização.

\section{Resultados}

O projeto de extensão utilizou redes sociais, através das contas @ifsp.saoroque.cex no Instagram, com 325 seguidores e Projeto-Covid SRQ, no Facebook, com aproximadamente 65 seguidores e uma média de 50 pessoas alcançadas por postagem, até o dia 17 de outubro de 2020. No período de 2 meses e meio foram realizadas 21 publicações, tanto no Instagram, como

$$
\begin{array}{l|l}
\multirow{2}{*}{\text { REVISTA }} & \text { EXTENSÃO \& CIDADANIA } \\
\cline { 2 - 3 } & \text { v. 8, n. 14, p. 248-265, jul./dez. 2020. ISSN 2319-0566 }
\end{array}
$$


no Facebook (Figura 1). As postagens tiveram 539 curtidas e 34 salvamentos no Instagram, e 77 curtidas e 16 compartilhamentos no Facebook, contando todas as postagens do período, até o dia 20 de outubro de 2020.

Figura 1 - Publicações feitas pelo projeto Ações extensionistas do IFSP São Roque no enfrentamento aos efeitos da Covid-19 e disponibilizadas nas redes sociais @ifsp.saoroque.cex e Projeto-Covid SRQ, no Instagram e Facebook respectivamente.
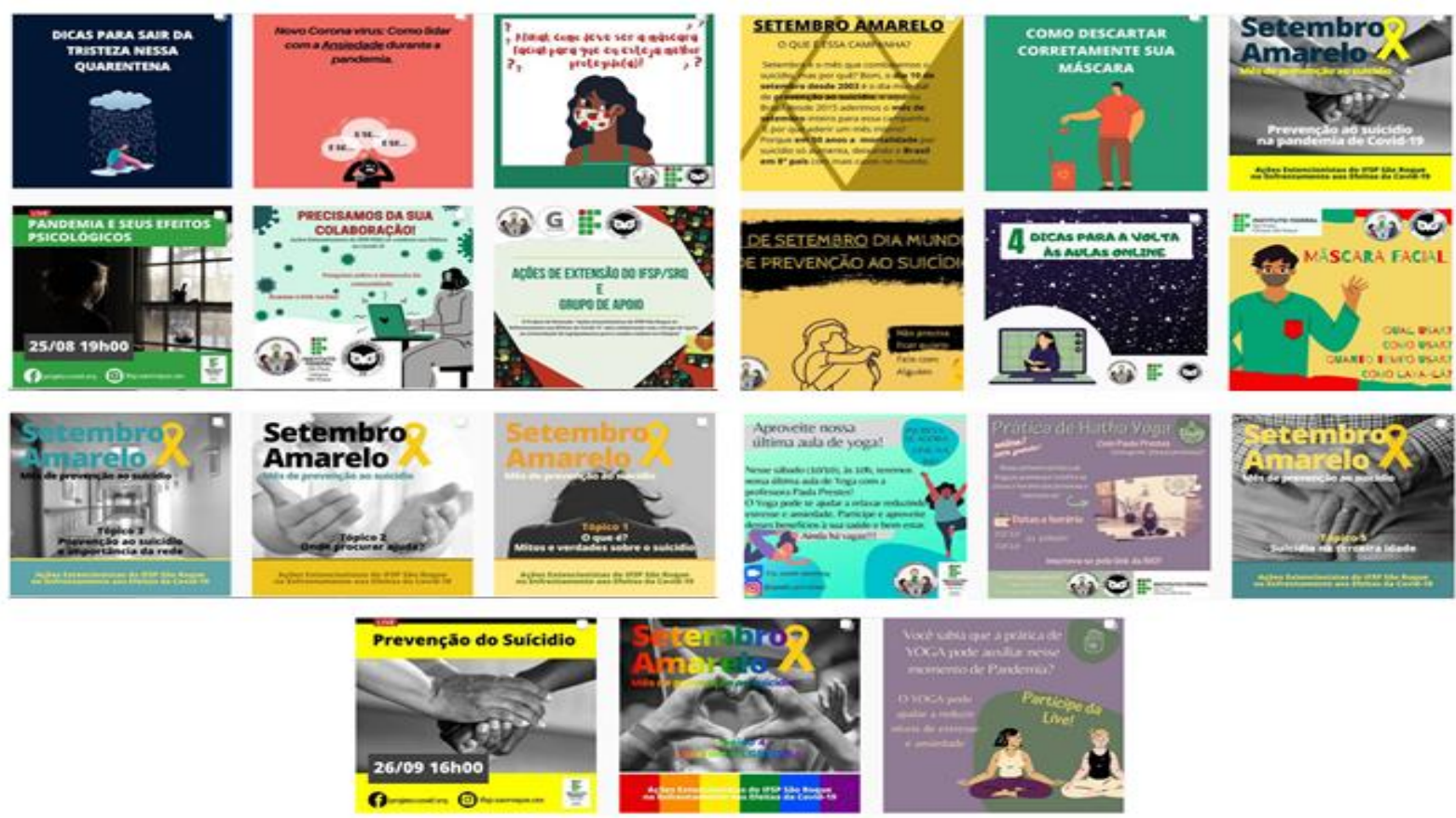

Fonte: Elaborada pelos autores.

As postagens possuem informações sobre: (a) o vírus causador da doença Covid-19; (b) métodos de prevenção e; (c) sugestões de como contornar consequências que o isolamento social (Figura 1). Entre as postagens feitas, a que abordou "quatro dicas para a volta às aulas online" teve maior alcance até o momento, possivelmente pelo fato de ter sido feita no período de retorno às aulas remotas do IFSP/SRQ, que ocorreu em setembro de 2020. O trabalho também realizou uma série de postagens sobre o setembro amarelo, na qual cada uma abordou

$$
\begin{array}{l|l}
\multirow{2}{*}{\text { REVISTA }} & \text { EXTENSÃO \& CIDADANIA } \\
\cline { 2 - 3 } & \text { v. 8, n. 14, p. 248-265, jul./dez. 2020. ISSN 2319-0566 }
\end{array}
$$


um aspecto específico do tema, entre eles: dia mundial da prevenção ao suicídio; prevenção ao suicídio na pandemia de Covid-19; o que é a campanha Setembro Amarelo; mitos e verdades sobre o suicídio; onde procurar ajuda; posvenção ao suicídio e importância da rede; suicídio e LGBTQIA+ e; suicídio na terceira idade. Em outro momento apresentou-se uma sequência de imagens com instruções sobre como lidar com ansiedade durante a pandemia, que obteve grande visibilidade. Postou-se também um conjunto de dicas de como sair da tristeza durante esse período de isolamento social.

Além disso, outras postagens e sequências de imagens informativas, também enfatizaram o uso de máscaras para prevenção da Covid-19. Entre as informações contidas, houve a descrição e importância do uso correto das máscaras, como fazer uma máscara segura, diferenças entre os tipos de máscara, diferenciando as máscaras caseiras de equipamentos de proteção respiratória e a descrição dos processos corretos de lavagem e utilização da máscara caseira.

O projeto também foi expandido para o canal no Youtube, IFSP-SRQ no Enfrentamento aos Efeitos da COVID, realizando a Transmissão de duas lives, ambas sobre o tema voltado à saúde mental e com apresentações e explicações de dúvidas por duas psicólogas diferentes. Estas transmissões tiveram duração aproximada de uma hora, período considerado longo se comparado a outras formas de utilização de rede social.

A primeira live ocorreu no dia 25 de agosto de 2020, com o título de "Pandemia e seus efeitos psicológicos" alcançando, até o dia 20 de outubro, o total de 139 visualizações. Nesta transmissão, foram abordados temas como ansiedade, adaptação às novas rotinas, sobretudo ao ensino remoto, e adoção de práticas que auxiliem na manutenção e preservação da saúde mental. A segunda live ocorreu no dia 26 de setembro de 2020 com o título "Prevenção do suicídio" e obteve, até o dia 20 de outubro, 61 visualizações. Apesar do menor número de pessoas alcançadas - talvez pelo possível receio ligado ao tema - houve um maior número de interações por meio de perguntas durante a transmissão ao vivo (Figura 2). 
Figura 2 - Foto tirada durante a live "Prevenção do suicídio", realizada em 26 de setembro de 2020, com uma pergunta feita por um dos participantes à psicóloga.

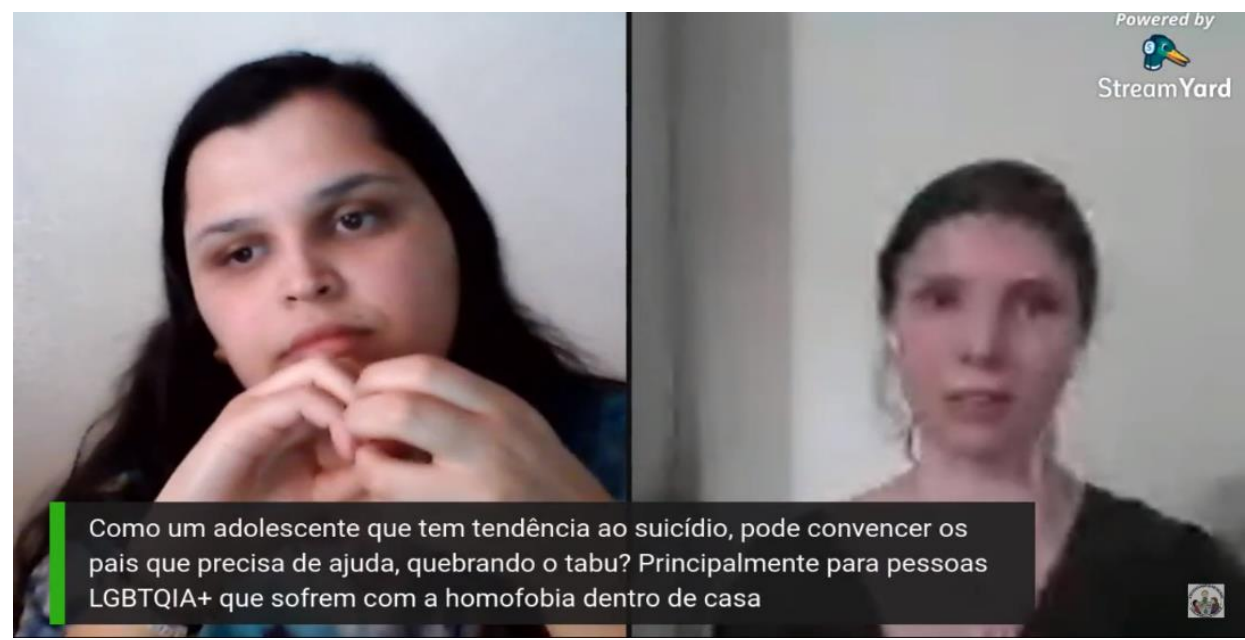

Fonte: Elaborada pelos autores.

Além disso, outra ação que ocorreu em setembro pelo Projeto de Extensão foi a realização de um minicurso de yoga, que tinha como objetivo principal incentivar a prática de atividades físicas em casa. A prática de yoga foi trazida como um exemplo de atividade possível de ser realizada na própria casa das pessoas e que pode trazer grandes benefícios a saúde física e mental que tanto foi debilitada devido ao isolamento social. $\mathrm{O}$ minicurso foi gratuito e aberto à comunidade interna e externa do IFSP/SRQ. Sobre esse curso, foram feitas 4 postagens no Instagram para a sua divulgação e inscrição das pessoas interessadas.

No mês de outubro, uma ação para comemoração ao dia das crianças foi realizada em parceria com o Centro de Referência de Assistência Social (CRAS), em São Roque, localizado no bairro Paisagem Colonial. A ação foi a elaboração, impressão e montagem de um livreto de atividades, composto por uma história em quadrinhos (HQ) e atividades como colorir, caça palavras e labirinto, entregue às crianças atendidas pelo CRAS, no dia 14 de outubro de 2020 .

A HQ também poderia ser colorida pelas crianças, desta forma, foram distribuídos junto

$$
\begin{array}{l|ll}
\multirow{2}{*}{\text { REVISTA }} & \text { EXTENSÃO \& CIDADANIA } \\
\cline { 2 - 3 } & \text { v. 8, n. 14, p. 248-265, jul./dez. 2020. } & \text { ISSN 2319-0566 }
\end{array}
$$


giz de cera ou lápis de cor. O objetivo dessa ação foi elaborar uma história acessível para crianças de diferentes idades entenderem, de forma lúdica, curiosidades sobre o vírus causador da doença Covid-19 e, também, reforçar a importância dos métodos de prevenção contra a doença. O caderno recebeu o título "As Aventuras de Lucas e Tom - fugindo da Covid-19" (Figura 3-A).

Foram distribuídos 150 unidades do kit composto pelo caderno de atividades e giz de cera ou lápis de cor, juntamente com um kit de doces oferecido pelo CRAS em comemoração ao Dia das Crianças (Figura 3-B).

Figura 3 - Ação em comemoração ao dia das crianças realizada em parceria com o Centro de Referência de Assistência Social (CRAS) em São Roque. (A) caderno "As Aventuras de Lucas e Tom - fugindo da Covid-19”; (B) distribuição dos kits para as crianças da comunidade.

A

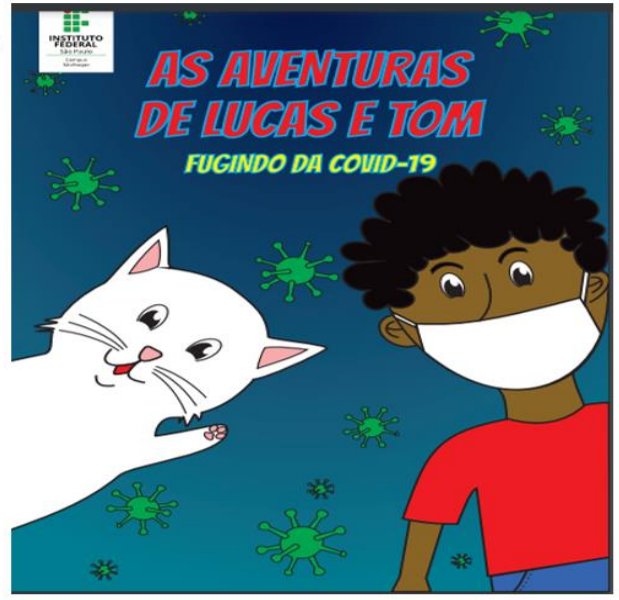

B

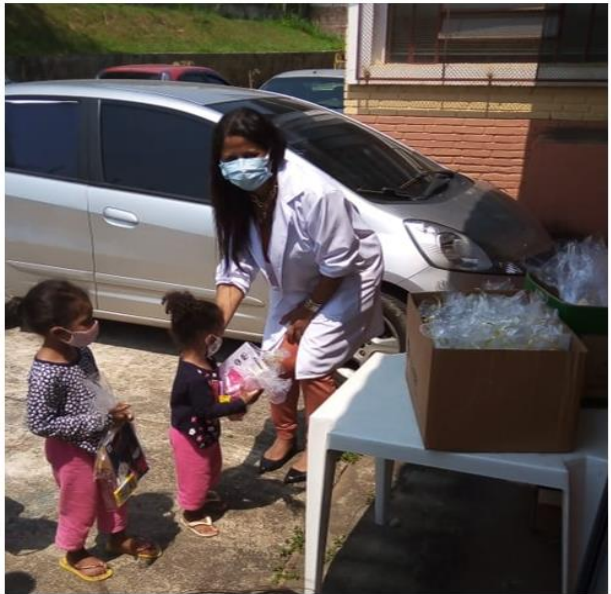

Fonte: Elaborada pelos autores.

O HQ está disponível no Instagram, @ifsp.saoroque.cex, e Facebook, Projeto-Covid SRQ, para impressão aos interessados pelo material. Essa acessibilidade das redes sociais permite a ampliação do acesso às ações extensionistas para além da cidade de São Roque. E foi realizada uma postagem voltada ao Dia das Crianças, descrevendo a ação de doação dos cadernos de atividades às crianças carentes.

Em relação à ação de doação de alimentos, a partir de algumas doações de alimentos e

$$
\begin{array}{l|l}
\multirow{2}{*}{\text { REVISTA }} & \text { EXTENSÃO \& CIDADANIA } \\
\cline { 2 - 3 } & \text { v. 8, n. 14, p. 248-265, jul./dez. 2020. ISSN 2319-0566 }
\end{array}
$$


recursos financeiros, o projeto começou a montagem de cestas básicas compostas por arroz, feijão, farinha, macarrão, sal e açúcar e, um kit higiênico com papel higiênico, pasta de dente, sabonetes, sabão em pedra, água sanitária e máscaras. As cestas que foram montadas para famílias maiores também contavam com achocolatados, bolachas e máscaras. A ação continuou até setembro de 2020 ano, quando foram entregues as últimas cestas (Figura 4).

Figura 4 - Campanha solidária de arrecadação e entrega das cestas básicas para famílias de São Roque e região realizada em parceria com o Grêmio Estudantil Mário de Andrade do IFSP/SRQ.

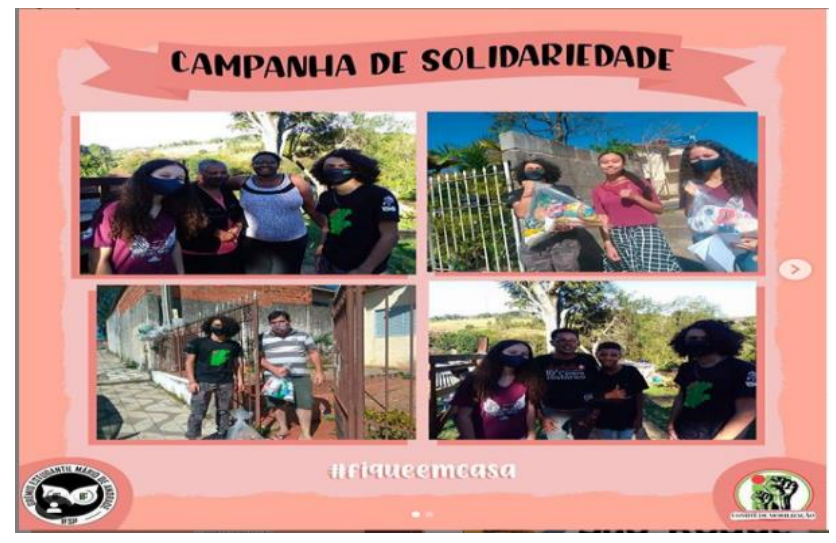

Fonte: Elaborada pelos autores.

\section{Discussão}

Um grande exemplo de demanda que surge a partir dessa nova realidade é que, durante uma pandemia, é esperado que estejamos frequentemente em estado de alerta, preocupados, confusos, estressados e com sensação de falta de controle frente às incertezas do momento. Estima-se que entre um terço e metade da população exposta a uma epidemia pode vir a sofrer alguma manifestação psicopatológica, caso não seja feita nenhuma intervenção de cuidado específico para as reações e sintomas manifestados.

Os fatores que influenciam o impacto psicossocial estão relacionados à magnitude da epidemia e ao grau de vulnerabilidade em que a pessoa se encontra no momento (BRASIL,

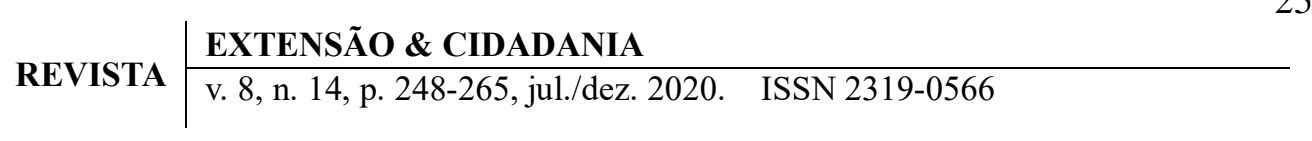


2020). Desta forma, as postagens em redes sociais e as lives que abordaram o tema da saúde mental, prevenção ao suicídio e como lidar com a ansiedade, diante de situações causadas pela pandemia Covid-19, são de grande relevância, tendo muita visibilidade, possivelmente pelo fato desses efeitos, juntamente com o stress, terem aumentado em vários grupos por causa do isolamento social, fator esse também evidenciado pela Organização Pan-Americana da Saúde, se baseando em dados da OMS de maio de 2020 (OMS, 2020).

Além disso, as redes sociais são uma das formas de manutenção da comunicação com grande parte da comunidade interna e externa do campus São Roque, ressaltando a sua importância, uma vez que as redes sociais no período da pandemia cresceram mais ainda, devido ao distanciamento social. Segundo Malavé e Mayra:

\footnotetext{
Enquanto as possibilidades do trabalho home office, aulas on-line, de adotar novas estratégias de comércio, manter relacionamentos afetivos e até desfrutar do lazer e da cultura já vinham ocorrendo nos últimos anos através das telas de smartphones e computadores, foi o isolamento social, devido ao surgimento do novo Coronavírus (Covid-19), que potencializou seu uso para conseguir manter certas rotinas durante a pandemia. (IFF, 2020, n. p.)
}

As postagens também demonstraram necessidades internas do Campus, pois a com maior número de visualizações foi sobre a volta às aulas de forma remota, que causou muita preocupação aos alunos da Instituição, mas que também é realidade em muitas outras escolas do Brasil e do mundo, já que esse período de volta às aulas evidenciou dificuldades variadas aos alunos e professores. Entre os problemas enfrentados com essa temática, podemos identificar a ansiedade causada nos alunos pela dificuldade de acesso e de recursos para participarem das aulas on-line. Nem toda a população tem acesso à internet e aos meios de comunicação, como constatada na pesquisa do IBGE (2018), onde 21\% dos domicílios brasileiros não tinham acesso.

A internet também permitiu uma interação dialógica junto ao público alvo, com o compartilhamento de informações e contribuindo com entretenimento no período de quarentena, em atendimento às demandas identificadas. $\mathrm{O}$ crescimento de lives (vídeos 
transmitidos ao vivo sobre temas variados, desde apresentações de cantores como informações sobre o vírus vindas de especialistas na área) também aumentaram (LUPINACCI, 2020). Outra vantagem é a permanência dos vídeos na plataforma Youtube, e a fácil localização do material posteriormente à transmissão ao vivo. A adoção deste formato ocorreu devido a necessidade de aprofundar os assuntos abordados em publicações escritas e imagens nas redes sociais e as escolhas dos temas ocorreram após a identificação de uma preocupação geral sobre o tema de saúde mental. Durante as lives foram fornecidas informações e explicações de dúvidas, além de buscar desmistificar crenças sobre o suicídio, tema este ainda muito estigmatizado e repleto de tabus, que dificultam a prevenção e disseminação de informações.

A ação do Dia das Crianças apresentou impacto significativo e positivo na comunidade, sendo evidente o interesse das crianças na história contada no formato de HQ ao receberem o material, que além de divertir, informou de maneira lúdica um tema tão atual e relevante quanto a Covid-19, falando sobre o vírus e formas de prevenção, auxiliando não só crianças e jovens, mas também adultos, pois a informação é simples, objetiva e possui linguagem clara. A história em HQ pode ser utilizada como um meio de informação para crianças alfabetizadas, jovens e adultos, estimulando a leitura, pois, quando a criança entra em contato com as histórias em quadrinhos, podem se sentir dispostas a também tentarem leituras mais complexas, como textos informativos, didáticos e até da literatura (SANTOS, 2001).

Segundo o Art. 4 do Estatuto da Criança e do Adolescente (ECA), toda criança e adolescentes devem ter garantidos o acesso à educação, assim como também a saúde, alimentação, cultura e outros (BRASIL, 1990). Adicionalmente, a Declaração Universal dos Direitos Humanos (1948) prevê o direito ao acesso à educação no Art. 26:

1. Toda pessoa tem direito à instrução. A instrução será gratuita, pelo menos nos graus elementares e fundamentais. A instrução elementar será obrigatória. A instrução técnico-profissional será acessível a todos, bem como a instrução superior, está baseada no mérito.

2. A instrução será orientada no sentido do pleno desenvolvimento da personalidade humana e do fortalecimento do respeito pelos direitos humanos e pelas liberdades fundamentais. A instrução promoverá a compreensão, a tolerância e a amizade entre todas as nações e grupos raciais ou religiosos, e coadjuvará as atividades das Nações 
Unidas em prol da manutenção da paz.

3. Os pais têm prioridade de direito na escolha do gênero de instrução que será ministrada a seus filhos. (DECLARAÇÃO UNIVERSAL DOS DIREITOS HUMANOS, 1948)

Mesmo sendo mostrado o direito por esses dois pilares e também pela Constituição Federal do Brasil no Art. 205 (BRASIL, 1988), foi registrada na matéria da Revista Época, em 2009, pela Jornalista Ana Aranha, que cerca de 1,8 milhão de alunos desistiram de estudar por alguns fatores: precisam trabalhar, não possuem acesso à escola, transporte e documentação e falta de interesse. Além disso, apenas $25 \%$ dos alunos dominam a língua portuguesa no terceiro ano.

Os fatores externos que colaboram, de certa maneira, com a evasão escolar no Ensino Fundamental se baseiam no nível socioeconômico dos alunos, tendo menor rendimento nos níveis econômicos mais baixos da população, enquanto os melhores rendimentos ocorrem nos grupos com recursos econômicos maiores (BRANDÃO; BAETA; ROCHA, 1983). E esses efeitos podem ser ainda mais acentuados com o isolamento social e efeitos do cancelamento das aulas presenciais causados pela Covid-19, nos níveis do Ensino Fundamental e Médio, havendo maiores chances de isso ocorrer devido à grande desigualdade que possibilita o aumento da evasão escolar causada pela exclusão digital dos alunos que não possuem acesso às tecnologias digitais, ou que não conseguem ser ajudados pelos pais que trabalham ou não conseguem explicar conteúdos complexos aos seus filhos (BATISTA, 2020).

\section{Considerações finais}

A Pandemia ocasionada pela Covid-19 provocou uma mudança forçada e repentina, causando medo, ansiedade e estresse em muitas pessoas, ao mesmo tempo em que, desde a sua confirmação no Brasil, também possibilitou a realização e visibilidade de muitos trabalhos de ajuda ao próximo, com a finalidade de minimizar os impactos provocados pelo isolamento social. Entre os trabalhos realizados, há o presente projeto apresentado, que procurou o seu

$$
\begin{array}{l|l}
\multirow{2}{*}{\text { REVISTA }} & \text { EXTENSÃO \& CIDADANIA } \\
\cline { 2 - 3 } & \text { v. 8, n. 14, p. 248-265, jul./dez. 2020. ISSN 2319-0566 }
\end{array}
$$


espaço, colaborando de várias formas e buscando ajudar o máximo possível de pessoas, levando informações confiáveis, com embasamento científico e promoção de bem-estar à comunidade interna e externa do Instituto Federal de São Paulo, campus São Roque, incluindo todos os grupos de diferentes faixas etárias. Desta forma, há a consolidação do projeto extensionista, ao agir promovendo a educação, desenvolvimento e difusão de conhecimentos, respeitando as articulações e relações entre instituições de ensino e os segmentos sociais.

\section{Referências}

ARANHA, A. A escola que os jovens merecem: a pior educação do país é oferecida no ensino médio. Cinco alunos revelam seu cotidiano escolar e apontam o que poderia ser melhor. Revista Época: globo.com, 2009. Disponível em: http://revistaepoca.globo.com/Revista/Epoca/0,EMI87998-15223,00A+ESCOLA+QUE+OS+JOVENS+MERECEM.html. Acesso em: 13 out. 2020.

BARRETO, M. L.; BARROS, A. J. D. de; CARVALHO, S. C.; CODEÇO, C. T.; HALLAL, P. R. C.; MEDRONHO, R de A.; STRUCHINER, C. J.; VICTORA, C. G.; WERNECK, G. L. O que é urgente e necessário para subsidiar as políticas de enfrentamento da pandemia de COVID-19 no Brasil? Revista Brasileira de Epidemiologia, Rio de Janeiro, v. 23, Epub 22abr. 2020.

BATISTA, R. Evasão escolar pode aumentar com pandemia, alertam debatedores. Senado Notícias. 2020. Disponível em: https://www12.senado.leg.br/noticias/materias/2020/07/09/evasao-escolar-pode-aumentarcom-pandemia-alertam-debatedores. Acesso em: 13 out. 2020.

BRANDÃO, Z.; BAETA, A. M. B.; ROCHA, A. D. C. da. Evasão e repetência no Brasil a escola em questão. Rio de Janeiro: Achiamé, 1983.

BRASIL. Ministério da Saúde. Painel de casos de doença pelo coronavírus 2019 (COVID19) no Brasil [Internet]. Brasília, DF: 2020a. Disponível em: https://covid.saude.gov.br/. Acesso em: 1 out. 2020.

BRASIL. Ministério da Saúde. Protocolo de manejo clínico para o novo coronavírus (2019-nCoV). Brasília-DF, 2020b. Disponível em: https://ead-

$$
\begin{array}{l|l}
\multirow{2}{*}{\text { REVISTA }} & \text { EXTENSÃO \& CIDADANIA } \\
\cline { 2 - 3 } & \text { v. 8, n. 14, p. 248-265, jul./dez. 2020. ISSN 2319-0566 }
\end{array}
$$


saude.dataprev.gov.br/pluginfile.php/46/mod_quiz/intro/protocolo.pdf. Acesso em: 26 maio 2020.

BRASIL. Instituto Federal de Educação, Ciência e Tecnologia de São Paulo (IFSP). PDI 2019-2023, 2019. 2019. Disponível em: https://ifsp.edu.br/images/pdf/PDI1923/PDI-20192023_Aprovado-CONSUP-12.03.2019.pdf. Acesso em: 13 out. 2020.

BRASIL. Lei $\mathbf{n}^{\circ}$ 11.892, de 29 de dezembro de 2008. Institui a Rede Federal de Educação Profissional, Científica e Tecnológica, cria os Institutos Federais de Educação, Ciência e Tecnologia. Disponível em: http://www.planalto.gov.br/ccivil_03/_Ato2007-

2010/2008/Lei/L11892.htm. Acesso em: 13 out. 2020.

BRASIL. Estatuto da Criança e do Adolescente. Lei n. 8.069, de 13 de julho de 1990.

Brasília, DF. Disponível em: http://www.planalto.gov.br/ccivil_03/leis/18069.htm. Acesso em: 13 out. 2020.

BRASIL. Constituição da República Federativa do Brasil. 1988. Disponível em: http://portal.mec.gov.br/setec/arquivos/pdf_legislacao/superior/legisla_superior_const.pdf. Acesso em: 13 out. 2020.

CHAN, J. F.; YUAN, S.; KOK, K. H. et al. A familial cluster of pneumonia associated with the 2019 novel coronavirus indicating person-to-person transmission: a study of a family cluster. Lancet, v. 395 (10223) p. 514-523, 20, 30154-30159, 2020.

DECLARAÇÃO UNIVERSAL DOS DIREITOS HUMANOS. Assembleia Geral das Nações Unidas em Paris. 10 dez. 1948. Disponível em: http://revistathemis.tjce.jus.br/index.php/THEMIS/article/viewFile/574/542. Acesso em: 19 out. 2020.

FREIRE, P. Extensão ou comunicação. Rio de Janeiro: Paz e Terra.1992.

IBGE. Instituto Brasileiro de Geografia e Estatística. Uso de internet, televisão e celular no Brasil. Brasil, 2020. Disponível em: https://educa.ibge.gov.br/jovens/materias-

especiais/20787-uso-de-internet-televisao-e-celular-no-brasil.html. Acesso em: 19 out. 2020.

IFF. Instituto Nacional de Saúde da Mulher, da Criança e do Adolescente Fernandes Figueira. O papel das redes sociais durante a pandemia. Rio de Janeiro, c2020. Disponível em: http://webcache.googleusercontent.com/search?q=cache:BYrRBLIEN1MJ:www.iff.fiocruz.br /index.php/8-noticias/675-papel-redes-sociais $+\& \mathrm{~cd}=3 \& \mathrm{hl}=\mathrm{pt}-\mathrm{BR} \& \mathrm{ct}=\mathrm{clnk} \& \mathrm{gl}=\mathrm{br}$. Acesso em: 19 out. 2020. 
JOHNS HOPKINS UNIVERSITY. Coronavirus COVID-19 global cases by Johns

Hopkins CSSE [Internet]. Johns Hopkins University, 2020. Disponível em: https://gisanddata.maps.arcgis.com/apps/opsdashboard/index.html\#/bda7594740fd402994234 67b48e9ecf6. Acesso em: 30 set. 2020.

KIRCHDOERFER, R. N.; COTTRELL, C. A., WANG, N. et al. Pre-fusion structure of a human coronavirus spike protein. Nature, v. 531(7592) p. 118-121, 2016.

LUPINACCI, L. "Da minha sala pra sua": Teorizando o fenômeno das lives em mídias sociais. Disponível em: file:///C:/Users/didaa/Downloads/960-Preprint\%20Text-1433-2-1020200714.pdf. Acesso em: 19 out. 2020.

OMS. Organização mundial de Saúde. Timeline - COVID-19. 2020. Disponível em: https://www.who.int/news-room/detail/27-04-2020-who-timeline---covid-19. Acesso em: 30 set. 2020.

SANTOS, R. E. dos. Aplicações da História em Quadrinhos. Comunicação \& Educação, [S . l.], n. 22, p. 46-51, 2001. DOI: 10.11606/issn.2316-9125.v0i22p46-51. Disponível em: http://www.revistas.usp.br/comueduc/article/view/36995. Acesso em: 13 out. 2020.

VASCONCELOS, M.C.R.L.; FERREIRA, M. A. T. A contribuição da cooperação universidade/empresa para o conhecimento tecnológico da indústria. Perspectiva Científica, Belo Horizonte, v. 5, n. 2, p. 167-182, 2000.

VEIGA, Cergio; BERGIANTE, Níssia. Fatores predominantes da evasão escolar no ensino médio profissional: uma revisão de literatura. In: XII CONGRESSO NACIONAL DE EXCELÊNCIA EM GESTÃO \& III INOVARSE 2016, RIO DE JANEIRO. Anais... Rio de Janeiro, 2016. Disponível em: https://www.inovarse.org/node/4583. Acesso em: 19 out. 2020.

WANG, Q.; WANG, Y. H.; MA, J. C. et al. Description of the first strain of 2019- nCoV, C-Tan-nCoV Wuhan Strain - National Pathogen Resource Center, China. 2020.

Disponível em: http://weekly.chinacdc.cn/en/article/id/e3a460f1-661b-4180-b562ecd8e9502082. Acesso em: 8 fev. 2020.

WHO World Health Organization. Coronavirus disease 2019 (COVID-19): situation report-30. 2019. Disponível em: https://www.who.int/docs/defaultsource/coronaviruse/situation-reports/20200219-sitrep-30-covid-19.pdf?sfvrsn=6e50645_2. Acesso em: 20 set. 2020.

ZHENG, Y., MA, Y., ZHANG, J. et al. COVID-19 and the cardiovascular system. Nat Rev Cardiol v. 17, 259-260, 2020. Disponível em: https://doi.org/10.1038/s41569-020-0360-5.

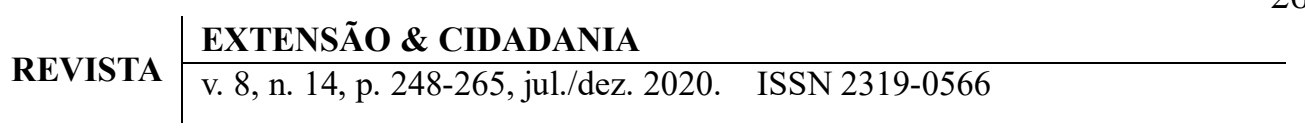


Acesso em: 13 set. 2020

ZHU, N, ZHANG, D, WANG, W, et al. A novel coronavirus from patients with pneumonia in China, 2019. N Engl J Med, v. 382(8), p. 727-733. 2020.

Recebido em: 21 de outubro de 2020.

Aceito em: 23 de novembro de 2020. 